\title{
EXPERIÊNCIA PILOTO EM ARBORIZAÇÃO PARTICIPATIVA EM DUAS CIDADES DE PEQUENO PORTE DO SEMI-ÁRIDO BRASILEIRO ${ }^{1}$
}

José Augusto de Lira Filho ${ }^{1}$, Clécio Maynard Batista da Fonseca ${ }^{2}$, Perla de Sousa Alves ${ }^{3}$, Roberta Maria de Albuquerque Lacerda ${ }^{4}$

(recebido em 09.04.2008 e aceito para publicação em 30.06.2009)

\section{RESUMO}

As árvores urbanas desempenham funções ecológicas, econômicas e sociais no espaço em que se inserem proporcionando vários benefícios à população. Submetidas a um clima quente e seco, as cidades do semi-árido brasileiro necessitam da presença de uma massa arbórea que Ihes proporcionem melhorias no padrão ambiental, garantindo-lhes, melhoria de vida das populações nelas inseridas. Este trabalho objetivou a aplicação do planejamento participativo na arborização urbana em cidades de pequeno porte do semi-árido paraibano. Foi avaliada a Arborização Participativa nas cidades de São Mamede e São José do Bonfim, ambas situadas no Território do Médio Sertão Paraibano, que poderão servir de modelo para as demais cidades similares da região. Neste trabalho realizaram-se a sensibilização da população, levantamentos preliminares (diagnóstico da arborização) e elaboração e execução do plano de arborização. Os resultados evidenciaram que em São Mamede há um déficit de 54\% de árvores a serem implantadas nas ruas, enquanto em São José do Bonfim este déficit é de 69,7\%. Constatou-se que em cidades de pequeno porte o planejamento participativo é tecnicamente viável, apesar do grau de complexidade operacional.

Palavras-Chave: Silvicultura urbana, planejamento participativo, paisagismo urbano.

\footnotetext{
${ }^{1}$ Professor Doutor em Paisagismo, Unidade Acadêmica de Engenharia Florestal/UFCG. Rua Sérgio Lima, n. 1020 - Bairro Jardim Guanabara, Patos - PB, CEP: 58.701-360. E-mail: augustoufcg@yahoo.com.br.

${ }_{2}$ Graduando em Engenharia Florestal, Universidade Federal de Campina Grande, Patos=PB, cleciomaynard@hotmail.com,

${ }^{3}$ Graduando em Engenharia Florestal, Universidade Federal de Campina Grande, Patos=PB, perlaperlinha@hotmail.com

${ }^{4}$ Mestranda em Ciências Florestais, Unidade Acadêmica de Engenharia Florestal/UFCG. Patos-PB, robertaufcg@yahoo.com.br
} 
EXPERIENCE PILOT IN THE PARTICIPATIVE FORESTATION IN TWO CITIES OF SMALL LOAD FROM SEMI-ARID BRAZILIAN

\begin{abstract}
The urban trees carry out ecological, economical and social functions in space where are inserted and providing several benefits to population. The cities of Brazilian semi-arid submitted to hot and dry climate, needs of the presence of arboreal mass to provide improvements in the environmental pattern, guaranteeing improvement of life of populations. This work aimed the application of participative planning in urban forestation in cities of small load of semi-arid region of Paraíba State, Brazil. Participative urban forestation has been evaluated in São Mamede, and São José do Bonfim (cites of Paraíba State) placed in Medium Sertão Paraibano Territory. These cities can serve as model for other similar cities of area. In this work was accomplished the population sensitiveness, preliminary risings (diagnosis of urban forestation) and elaboration and execution of urban forestation plan. The results evidenced what in São Mamede there is a deficit of $54 \%$ of trees to be implanted, while in São José do Bonfim this deficit is of $69,7 \%$. In these work was verified that in cities of small load the participative planning is technically viable, in spite of the degree of operational complexity.
\end{abstract}

Key-words: Urban forestation, participative planning, urban landscape.

\title{
INTRODUÇÃO
}

As árvores urbanas ao desempenharem funções ecológicas, econômicas e sociais no espaço em que se inserem, proporcionam vários benefícios à população. Em termos ecológicos, Paiva e Gonçalves (2004), enunciam que as mesmas concorrem para os controles de temperatura, poluição, ciclo hidrológico e ruídos, além de servirem para estruturação dos espaços, bem como no auxílio da ventilação e no desempenho de elemento referencial. Por outro lado, árvores urbanas ainda podem desempenhar funções de proteção do meio ambiente, de produção, além dos benefícios sociais incidentes, direta e indiretamente, sobre as comunidades urbanas.

As cidades do semi-árido brasileiro estão submetidas a um clima quente e seco, do tipo Bsh conforme classificação de Koppen-Geigertipo, com até nove meses de estiagem, 
Experiência piloto em arborização participativa...

necessitam da presença de uma massa arbórea que Ihes proporcione melhorias no padrão ambiental, garantindo-lhe, conseqüentemente, uma melhoria de vida das populações nelas inseridas. Em sua maioria, a arborização dessas cidades não passou por um planejamento prévio e, em conseqüência, podem apresentar sérios problemas de manejo. Segundo Milano e Dalcin (2000), mesmo aquelas cidades em que a arborização foi planejada também podem apresentar problemas por falta de avaliações constantes para replanejamento e atualização do plano diretor.

Nas cidades de pequeno porte do Sertão paraibano, o planejamento da arborização não faz parte da práxis da gestão ambiental. Inexistindo um plano a seguir e cumprir, conforme elucidam Milano e Dalcin (2000), o processo de implantação e manejo da arborização segue procedimentos puramente empíricos.

Preocupados com essa realidade e na tentativa de reverter esse processo, a área de Paisagismo da Unidade Acadêmica de Engenharia Florestal da Universidade Federal de Campina Grande elaborou um projeto piloto de extensão tendo com foco de atividades o planejamento da arborização dessas cidades do semi-árido paraibano.

\section{MATERIAIS E MÉTODOS}

No Sertão paraibano, o Poder Público de alguns municípios sensibilizados em adotarem uma nova postura na gestão ambiental assinalaram interesse em deflagrarem um processo de Arborização Participativa em suas sedes municipais em parceria com a Unidade Acadêmica de Engenharia Florestal/UFCG. Neste sentido, objetivando experienciar a aplicação do planejamento participativo na arborização urbana, direcionou-se esta pesquisa para as cidades de São Mamede e São José do Bonfim, ambas de pequeno porte localizadas no semi-árido paraibano (Figuras 1 e 2), as quais servirão de modelo para as demais cidades similares na região. 


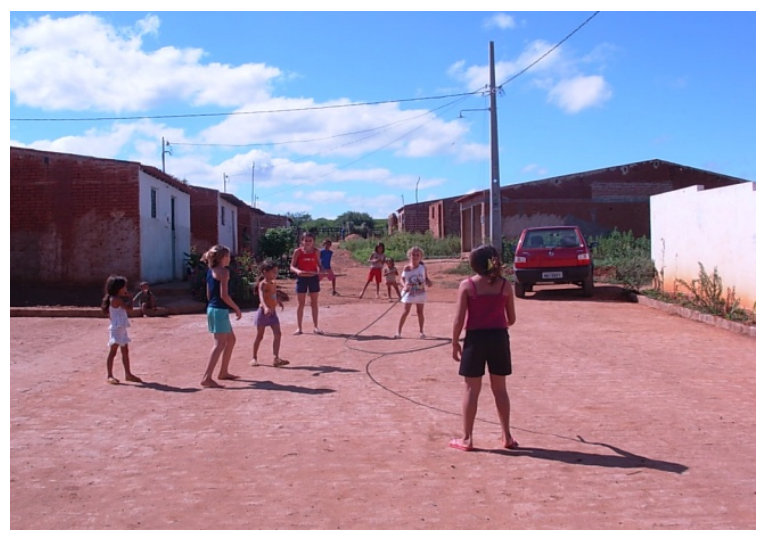

Figura 1. Rua a ser arborizada em bairro periférico na cidade de São José do Bonfim, Sertão Paraibano.

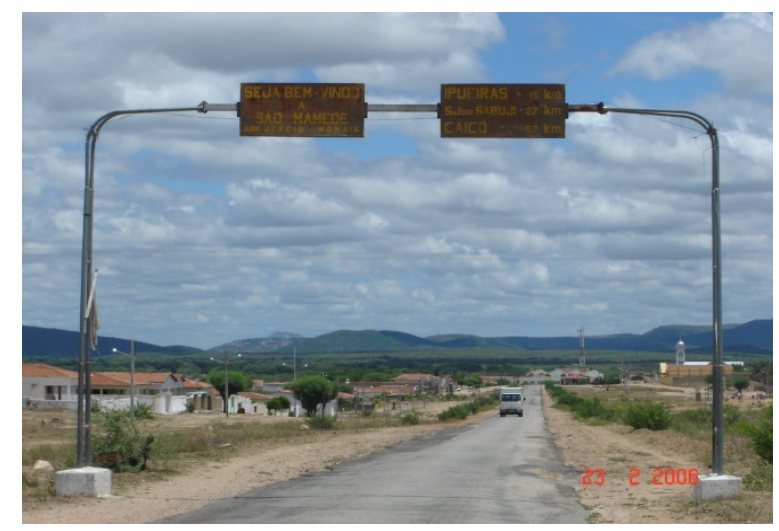

Figura 2. Avenida de acesso principal da cidade São Mamede, no Sertão Paraibano, apresentando ausência de espécimes arbóreos.

As cidades pesquisadas enquadram-se na categoria de pequeno porte por apresentarem populações de 8.018 e 2.837 habitantes, respectivamente para São Mamede e São José do Bonfim. De características tipicamente rurais, essas cidades localizam-se no Sertão paraibano, sendo que a primeira está inserida na microrregião do Seridó Ocidental e a segunda na Serra do Teixeira.

Em termos metodológicos, esta pesquisa foi realizada em três vertentes distintas: a) Sensibilização da população alvo, b) Levantamentos preliminares (diagnóstico da arborização), e c) Elaboração e execução do plano de arborização.

\section{a) Sensibilização da população alvo,}

Quanto ao processo participativo, na prática cotidiana da silvicultura urbana Lira Filho (2000) enuncia que no Brasil tem se verificado rotinas clássicas de imposições de padrões 
Experiência piloto em arborização participativa...

estéticos e funcionais, alheios ao apelo da sociologia e psicologia, em que a população alvo não tem a oportunidade sequer de opinar sobre as espécies que desejam ter nas ruas. Tal fato também tem foi constatado nas cidades paraibanas, onde se executa uma arborização convencional, sem aplicação do planejamento participativo.

O processo de arborização participativa iniciou-se com a sensibilização da população alvo, utilizando-se dos mais variados meios (oficinas para construção do processo participativo com os atores sociais, divulgação do projeto na mídia convencional e alternativa). A partir do momento em que a população é envolvida concretamente no processo de Arborização Urbana, tal atividade se constitui em um ato de cidadania e, por si só, um processo de Educação Ambiental (PAIVA e GONÇALVES, 2002). Ainda segundo estes autores, a aglomeração de indivíduos arbóreos nas cidades auxilia na qualidade de vida da população no tocante aos produtos gerados e pode reverter-se em serviços sob forma de emprego e renda, contribuindo para elevação do padrão social das comunidades envolvidas. Entretanto, vale salientar que na Arborização Urbana propriamente dita o Poder Público Municipal é marcado pela instrumentação subsidiária, planejando tecnicamente de forma competente, assumindo seu compromisso de serviço público quantitativo e qualitativo (DEMO, 1991). Além disso, os atores sociais devem ter consciência crítica de seus papéis no processo participativo (LIRA FILHO, 2003).

Realizou-se, nesse primeiro momento, uma série de atividades de educação ambiental a fim de que a população se inteirasse sobre os benefícios proporcionados pela presença de árvores nas vias públicas e áreas verdes das cidades. Neste contexto, foram utilizadas técnicas de educação ambiental sugeridas por Brasil (1997), Pedrini (1998), Souza e Reis (2003), Hammes (2004) e Dias (2004). A população foi trabalhada em diferentes faixas etárias e níveis de escolaridade. Contou-se com a participação de entidades tais como escolas públicas, paróquias, associações de bairros, entre outras entidades da sociedade civil.

\section{b) Diagnóstico da arborização}

Para se obtenção das informações quali-quantitativas da arborização presente nas cidades pesquisadas, utilizou-se os inventários que, segundo Silva (2007), pode ser classificado quanto à intensidade em completos (totais, censo) ou amostrais. Inventários totais são recomendados por MILANO e DALCIN (2000), em caso de áreas pequenas, tais mo as cidades de pequeno porte. Apesar das cidades pesquisadas se enquadrarem nesta justificativa dos desses autores, utilizou-se como critério de escolha para a modalidade do inventário, a dimensão territorial urbana. No caso de São José do Bonfim, por possuir menor 
área, utilizou-se o censo, enquanto que em São Mamede optou-se pela amostragem de $10 \%$ da arborização.

Os dados foram coletados por meio de observações "in loco" das árvores urbanas ocorrentes apenas nas vias públicas, sendo preenchido um formulário padrão constando variáveis ineterntes às árvores e a infra-estrutura local. Analisaram-se os seguintes parâmetros, considerados desejáveis para a realidade local: $n^{\circ}$ da edificação, nome popular da espécie, fitossanidade, problemas de raiz, largura do passeio, afastamento predial, fiação, diâmetro a altura do peito (DAP), copa longitudinal, avanço da copa para a rua, avanço da copa para a edificação, altura total, altura da primeira bifurcação, e necessidade de podas.

\section{c) Elaboração e execução do plano de arborização.}

De posse do diagnóstico da massa arbórea urbana e, paralelamente aos trabalhos de sensibilização e conscientização da população alvo, realizou-se a fase de planejamento participativo em que as comunidades locais bem como as instituições envolvidas no projeto tiveram a oportunidade de participarem das decisões tomadas no que concerne às etapas posteriores desenvolvidas, ou seja, a implantação das árvores urbanas e a sua manutenção, inseridas no Plano Diretor de Arborização. Os diagnósticos foram apresentados e discutidos em audiência pública aos Conselhos Municipais e Meio ambientes, contando-se também com a presença dos Poderes Executivo e Legislativo, diretores de escolas e líderes comunitários dos bairros.

Nesta fase da pesquisa, o processo do Planejamento Participativo foi implementado levando-se em consideração que a participação se manifesta por ações participativas de caráter instrumental ou substantivo (BORDENAVE e CARVALHO, 1987) e as origens de ambas estão na consciência. Essa conscientização pode ser entendida como um processo contínuo de compreensão crítica da realidade a partir de uma interação entre o agente externo e a população (SOUZA, 1993). Para isto utilizou-se técnicas de Educação Ambiental recomendadas por Pedrini (1998), Hammes (2004), Souza e Reis (2003), Dias (2004).

\section{RESULTADOS E DISCUSSÃO}

Constatou-se que em São José do Bonfim apenas 34\% da população reside na cidade enquanto que em São Mamede este índice é de 70\%. Nesse sentido, apesar das características rurais de ambas, os Planos Diretores de Arborização mereceram tratamentos diferenciados devido aos diferentes níveis de concentração da população urbana. 
Experiência piloto em arborização participativa...

Os diagnósticos revelaram que do ponto de vista de infra-estrutura viária as cidades se assemelham apresentando ruas largas e passeios estreitos. Nesta condição, para compatibilização da arborização urbana, CEMIG (2001) recomenda que sejam plantadas espécies de pequeno e médio portes do lado onde não houver fiação, 0,50 $\mathrm{m}$ fora do passeio, se não houver afastamento entre a edificação e o passeio. Entretanto, ainda segundo o mesmo autor, se houver recuo da edificação, o plantio poderá ser feito com árvores de pequeno porte no passeio. Ressalta-se que, para a realidade do Sertão paraibano, a concessionária de energia elétrica não disponibiliza de tecnologia de proteção da fiação em relação aos galhos das árvores. Apesar dessa negligência da concessionária e considerando que é imprescindível a presença de massa arbórea para propiciar melhorias microclimáticas, acatou-se a recomendação do autor supracitado o qual recomenda o uso de árvores de pequeno porte no lado da rua com fiação aérea.

Através do levantamento amostral da arborização de ruas e avenidas em São Mamede, constatou-se que a mesma possui certa heterogeneidade, sendo encontradas 12 espécies, as quais 61\% representada por Algaroba (Prosopis juliflora), seguida de 12,3\% de Fícus (Ficus spp.), além da Castanhola (Terminalia catappa) e Cássia seamea (Senna seamea) que obtiveram a terceira maior ocorrência com um percentual de $7 \%$ cada (Tabela $1)$.

Tabela 1. Ocorrência das quatro espécies mais freqüentes na arborização de ruas em São Mamede, Sertão Paraibano.

\begin{tabular}{llrr}
\hline Nome popular & Nome científico & No $^{\circ}$ de árvores & $\%$ \\
\hline Algaroba & Prosopis juliflora & 174 & 60,84 \\
Fícus & Fícus spp & 35 & 12,24 \\
Castanhola & Terminalia catapa & 20 & 6,99 \\
Cássia seamea & Senna seamea & 20 & 6,99 \\
& & & \\
\hline
\end{tabular}

Por outro lado, verificou-se que em São José do Bonfim dentre as espécies mais freqüentes três são de grande porte com 60\% de Fícus (Fícus spp), 15\% de algaroba (Prosopis juliflora) e 7\% de cássia seamea (Senna seamea), conforme o Tabela 2. As espécies Algaroba e Castanhola além de possuírem grande porte, suas raízes superficiais prejudicando a infra-estrutura urbana. Além disso, o Ficus spp também é de grande porte e possui sistema radicular bastante agressivo, com o agravante de não ser uma espécie adequada para a região. Para Gonçalves e Paiva (2004) a classificação das árvores urbanas quanto ao porte é um tanto quanto difícil de se proceder já que esses espécimes 
vão de porte arbustivo a arbóreo sem se ter como separá-los em medidas, embora, para efeitos práticos, consideram árvores de grande porte as que ultrapassam os vinte metros de altura quando adultos. Entretanto, para a realidade do semi-árido brasileiro, pode-se classificar na categoria de grande porte as árvores com altura superior a quinze metros tais como as citadas anteriormente, todas exótica inseridas na região há bastante tempo.

Tabela 2. Ocorrência das quatro espécies mais freqüentes na arborização de ruas em São José do Bonfim, Sertão Paraibano.

\begin{tabular}{llcc}
\hline Nome popular & Nome científico & No de árvores & $\%$ \\
\hline Algaroba & Prosopis juliflora & 45 & 15 \\
Fícus & Fícus spp & 183 & 60 \\
Castanhola & Terminalia catapa & 09 & 03 \\
Cássia seamea & Senna seamea & 23 & 07 \\
& & & \\
\hline
\end{tabular}

Analisando-se a ocorrências das espécies mais freqüentes em ambas as cidades pesquisadas verifica-se que, a exceção da Senna seamea, as demais são inadequadas para plantio nas ruas e avenidas. Uma total ausência de planejamento da arborização tem sido responsável por tal realidade, acarretando sérias conseqüências negativas ao ecossistema urbano. Sobre esse fato, Machado (1999) elucida que na gestão da arborização nas principais cidades nordestinas, as soluções ainda são tímidas e casuísticas, predominando alguns entraves tais como o modismo. Os diagnósticos revelaram índices elevados de Fícus spp, também constatados em estudos realizados nas cidades do Agreste e Sertão paraibano por Meneses et al (2003), Melo et al (2007), Rodolfo Júnior (2008) e Araújo et al (2009). Essa espécie possui uma grande capacidade de desenvolvimento do sistema radicular, considerado inadequado para a arborização de vias públicas.

$\mathrm{Na}$ cidade de São Mamede, os espécimes arbóreos implantados encontram-se em diferentes fases de desenvolvimento, conforme ilustrado na Figura 3. Verificou-se que $73 \%$ das espécies se encontram na fase adulta; seguida de $20 \%$ na fase de muda e apenas $7 \%$ na fase juvenil. Tais números revelam que a arborização da cidade foi implantada há bastante tempo, muito embora não foi planejada, implantando-se espécies inadequadamente nos logradouros. Segundo Mllano e Dalcin (2000) a escolha inadequada das espécies arbóreos gera uma variedade de conflitos decorrentes, sobretudo, da interferência na infra-estrutura urbana. 
Experiência piloto em arborização participativa...

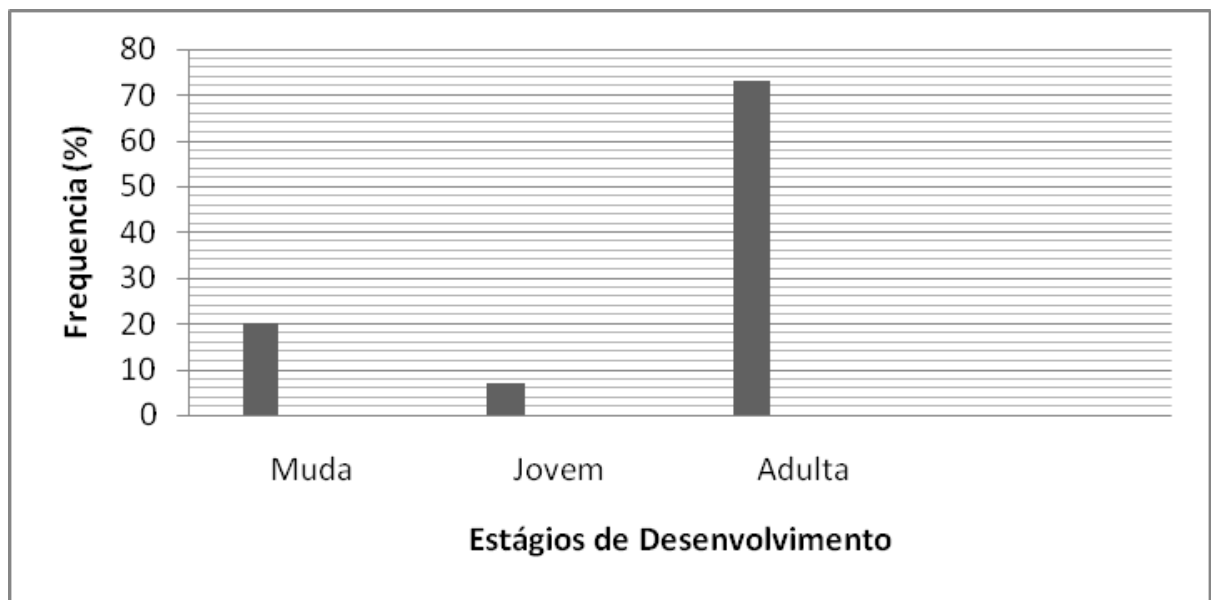

Figura 3. Fases de desenvolvimento das espécies arbóreas encontradas na arborização de vias publicas em São Mamede/PB

O diagnóstico da Arborização de ruas da cidade de São José do Bonfim/PB revelou um total de 22 espécies identificadas, com árvores em diferentes fases de desenvolvimento, conforme ilustrado na Figura 4.

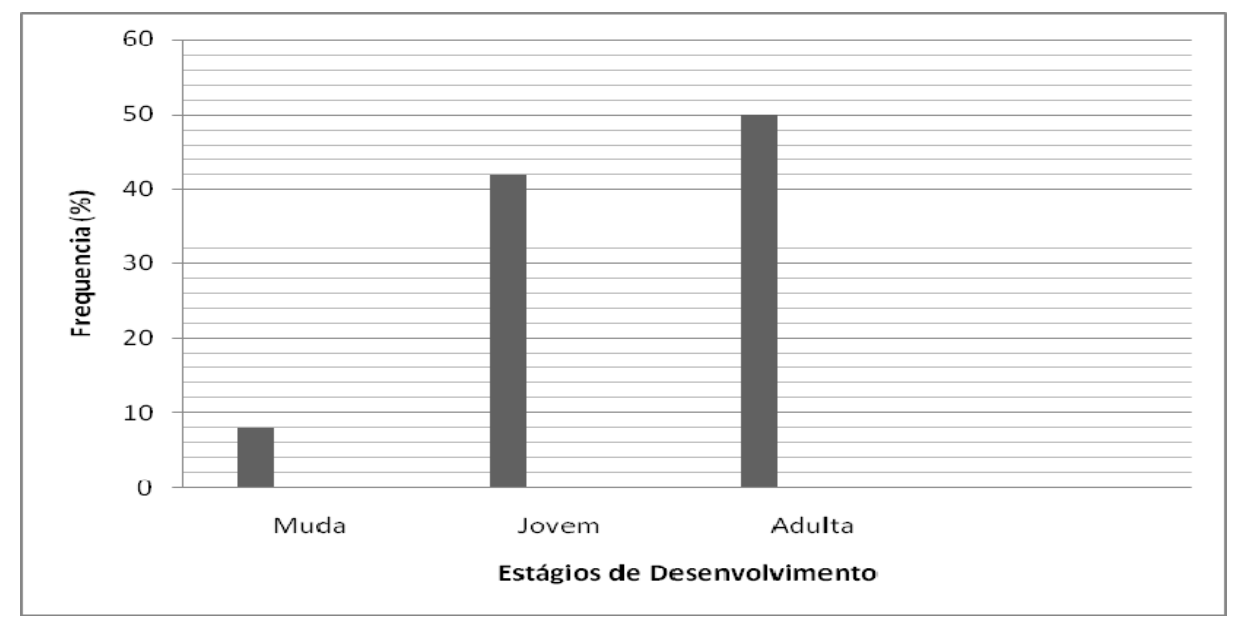

Figura 4. Fases de desenvolvimento das espécies arbóreas encontradas na arborização de vias publicam em São José do Bonfim.

Analisando-se a Figura 4, verifica-se que 50\% das espécies se encontram na fase adulta; seguida de $42 \%$ na fase juvenil e apenas $8 \%$ na fase de muda. Tais dados também são reveladores de que a arborização da cidade, assim como em São Mamede, a maioria foi implantada há bastante tempo, já outras foram implantadas há pouco tempo (mudas e jovens). 
Em termos de fitossanidade, verificaram-se em ambas as cidades uma situação muito boa das árvores. Em São Mamede o índice foi de 89\% na categoria "boa", enquanto que em São José do Bonfim observou-se um índice de 93,4\%, de acordo com a ilustração das Figuras 5 e 6 . Estes índices são indicadores de ótima qualidade fitossanitária das espécies, dispensando tratos silviculturais mais complexos e onerosos.

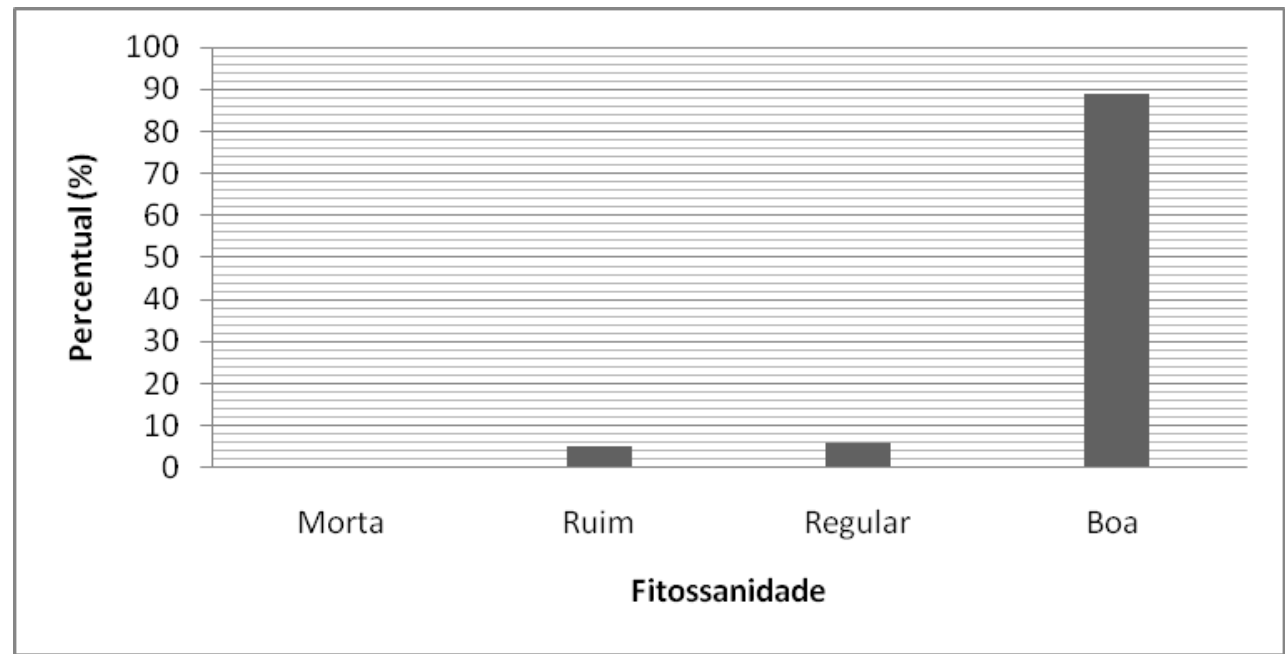

Figura 5. Situação fitossanitária das árvores nas ruas de São Mamede, Sertão Paraibano.

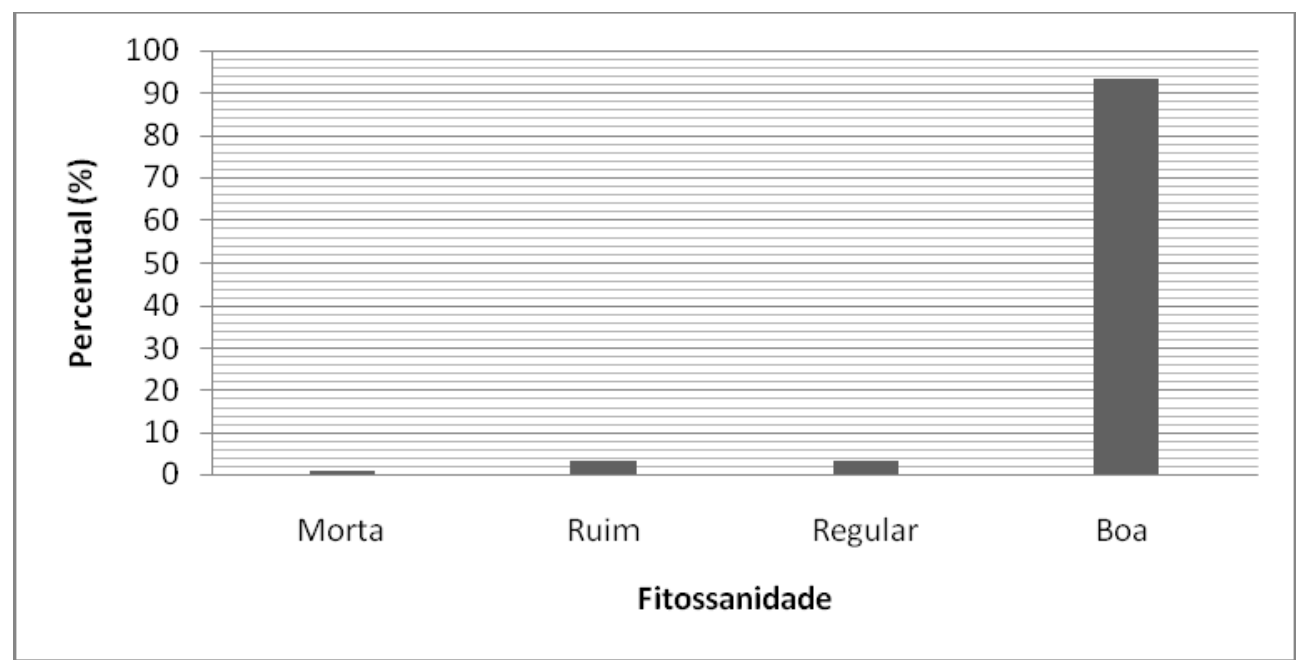

Figura 6. Situação fitossanitária das árvores nas ruas de São José do Bonfim, Sertão Paraibano.

Para a reforma da situação atual na arborização das cidades contempladas no projeto, verificou-se que em São Mamede há um déficit de $54 \%$ de árvores a serem implantadas nas ruas da cidade, enquanto que em São José do Bonfim este déficit é de $69,7 \%$. Estes índices demonstram a total falta de planejamento na arborização das cidades. 
Experiência piloto em arborização participativa...

A participação comunitária na arborização tem sido recomendada como forma de educação ambiental (PAIVA e GONÇALVES, 2002) e, conseqüentemente, como formadora de uma consciência crítica sobre as questões ambientais urbanas. Verificou-se nas oficinas de construção do Plano de Arborização Participativa nas cidades uma grande receptividade por parte da população alvo e das instituições envolvidas na arborização urbana.

Em São Mamede a participação dos Programas Sociais Municipais (Programa de Erradicação do Trabalho Infantil- PETI, Programa de Saúde da Família -PSFF, Casa da Família, Agente Jovem, Segundo Tempo, etc) foi de extrema importância para a consolidação do Plano Diretor de Arborização, além da presença fundamental dos órgãos públicos municipais (Executivo e Legislativo), bem como das escolas públicas, rádio comunitária e concessionárias de serviços públicos (eletrificação, telefonia, saneamento de água e esgotos). Nas escolas contou-se com a participação de pais e responsáveis pelos alunos, tendo-se trabalhado o conteúdo de forma multidisciplinar.

Já em São José do Bonfim, o Poder Público municipal foi representado pelas Secretarias de Agricultura e Educação, as quais tiveram disponibilizaram seus funcionários nas fazes de planejamento e execução da arborização urbana. Além disso, contou-se também com a participação direta da população urbana. Também se trabalhou a sensibilização dos alunos nas escolas municipais, nos mesmos moldes da outra cidade pesquisada. Para a divulgação e sensibilização do público alvo, priorizaram-se atividades em eventos populares tais como Festas Juninas, da Padroeira, Festa da Galinha de Capoeira, dentre outras. Além disso, contou-se com o apoio das rádios comunitárias.

A escolha das espécies no processo de arborização participativa tem se revelado um dos itens mais complexos, em decorrência do conflito entre o gosto popular e as recomendações técnicas. Especificamente em relação à frutescência, Paiva e Gonçalves (2004) alegam que espécies de frutos grandes podem representar perigo para pedestres e veículos estacionados nas vais públicas, além de serem impróprios para o consumo humano devido á contaminação por poluentes lançados nas cidades em decorrência da poluição dos veículos e indústrias.

Nas cidades pesquisadas não surpreendeu a preferência da maioria da população por espécies frutíferas, em se tratando de cidades caracteristicamente rurais. Nos trabalhos de sensibilização e construção do plano de arborização, em que não se impôs uma lista de espécies a serem selecionadas, verificou-se uma grande preferência por Mangifera indica, espécie com frutos de porte médio. Entretanto, pesquisa sobre arborização participativa realizada em Americana/SP, Silva et al (2007) também constaram essa preferência por frutíferas, sendo a Eugenia involucrata (de frutos pequenos) uma das mais votadas entre uma lista de espécies sugeridas aos moradores. No caso das cidades do semi-árido, trabalhos de conscientização foram intensificados a fim de reverter esse processo de 
escolha inadequada, sugerindo-se também uma lista de espécies mais apropriadas à região e compatíveis com a arborização de vias públicas.

Elaboraram-se os planos de arborização em ambas as cidades, em curto prazo (quatro anos). No primeiro ano de implantação do projeto (2007), foram plantadas 560 árvores em São Mamede e 506 em São José do Bonfim, ficando o restante para execução dos planos nos anos posteriores.

\section{CONCLUSÕES}

Como ocorre na maior parte das cidades brasileiras, verificou-se que a falta de planejamento da arborização urbana nas cidades pesquisas também é comum. Entretanto, detectou-se que na região os Poderes Públicos Municipais têm sido cobrados pela sociedade civil organizadas para a elaboração de Planos Diretores de Arborização. Tal fato demonstra certo avanço de consciência ambiental tanto por parte da população urbana quanto dos seus administradores.

Com relação à escolha das espécies arbóreas, constou-se que são utilizadas poucas espécies nativas na silvicultura urbana dando lugar a uma variedade de exóticas, inclusive não adaptadas ao ecossistema urbano da região.

Em termos de infra-estrutura urbana, em geral, as cidades estudadas são similares com predominância de ruas largas e passeios estreitos, apresentando condições para plantio de árvores dentro do princípios técnico e científico.

Apesar de complexa, esta pesquisa revelou que a introdução do processo participativo é plenamente viável na arborização em cidades de pequeno porte e que a população tem se sensibilizado bastante no que concerne aos benefícios sobre a presença da massa arbórea nas cidades.

\section{REFERÊNCIAS}

AMORESE, R. M. Comunicação participativa como prática cultural. Um enfoque para extensionis tas. Brasília: EMBRATER, 1984.ARAÚJO, C.A.; RIBEIRO, I.A.;

BORDENAVE, J. D., CARVALHO, H. M. O que é participação. São Paulo: Brasiliense, 1987. $47 \mathrm{p}$.

BRAGA, G. M. Planejamento em extensão rural. Viçosa: UFV, 1998. 18 p. (notas de aula) 
Experiência piloto em arborização participativa...

BRASIL, Secretaria de Educação fundamental. Parâmetros curriculares nacionais: meio ambiente, saúde. Brasília: SEF, Cima, 1997. 198 p.

COMPANHIA ENERGÉTICA DE MINAS GERAIS/ CEMIG. Manual de arborização. Belo Horizonte: CEMIG, 2001. 40 P.

DIAS, G. F. Educação ambiental - princípios e práticas. 9 ed. São Paulo: Gaia, 2004. $551 \mathrm{p}$.

DEMO, P. Participação e planejamento - arranjo preliminar. Revista da Administração Pública. v. 25, n. 3, p. 31-54, 1991.

GONÇALVES, W.; PAIVA, H. N. Árvores para o ambiente urbano. Viçosa-MG: Aprenda Fácil, 2004. 243 p.

HAMMES, V. S. Ver - percepção do diagnóstico ambiental, volume 3/EMBRAPA. São Paulo: Globo, 2004. 228 p. (Educação ambiental para o desenvolvimento sustentável)

LIRA FILHO. J. A . Arborização participativa: implicações na qualidade das florestas urbanas. Viçposa: UFV, 2003. Tese (Doutorado em Ciência Florestal) - Universidade Federal de Viçosa, 2003.

LIRA FILHO, J.A. Arborização urbana participativa: novo paradigma da silvicultura urbana? Ação Ambiental. Viçosa: UFV, p. 29, 2000.

MACHADI, J.R.M. Notas sobre a arborização nordestina. Boletim da SBAU... Rio de Janeiro: SBAU, v. 2, n. 1. p. 8

MELO, R.R.; LIRA FILHO, J.A.; RODOLFO JÚNIOR, F.R. Diagnóstico qualitativo e quantitativo da arborização urbana no bairro Bivar Olinto, Patos, Paraíba. Revista da Sociedade Brasileira de Arborização Urbana. Piracicaba: SBAU, v.2, n. 1, 2007.

MENESES, C.H.S.G.; SOUSA, E.B.M.; MEDEIROS, F.P.M.; MENEZES, I.R.; ALBUQUERQUE, H.N.; SANTOS, L. Análise da arborização dos bairros de Mirante e Vila Cabral na cidade de Campina Grande-PB. Revista da Sociedade Brasileira de Arborização Urbana . Piracicaba: SBAU, v.3, n. 2, 2003. 
MILANO, M.S..; DALCIN, E. Arborização de vias públicas. Rio de Janeiro: Ligth, 2000. $226 \mathrm{p}$.

MORAIS, M.S.; ARAÚJO, J.L.M. Análise quali-quantitativa da arborização no bairro Presidente Médici, Campina Grande-PB. Revista Sociedade Brasileira de Arborização Urbana. Piracicaba: SBAU, v.4, n. 1, 2009. p. 133-144

PAIVA, H.N.; GONÇALVES, W. Florestas urbanas: planejamento para melhoria da qualidade de vida. Viçosa: Aprenda Fácil Editora, 2002. 180 p.

PAIVA, H.N.; GONÇALVES, W. Árvores para o ambiente urbano. Viçosa: Aprenda Fácil Editora, 2004. 180 p. 2442 p.

PEDRINI, A. G. Educação ambiental, reflexões e práticas contemporâneas. Petrópoles(RJ): Vozes, 1998. 165 p.

SOUZA, I.P.F; REIS, E.S. Educação para convivência com o semi-árido. São Paulo: Petrópolis, 2003. 34 p.

RODOLFO JÚNIOR, F.R.; MELO, R.I.; CUNHA, F.A. STANGELIN, D.M. Análise da arborização urbana em bairros da cidade de Pombal no Estado da Paraíba. Revista Sociedade Brasileira Arborização Urbana. Piracicaba: SBAU, v.3, n. 4, 2008. p. 03-19

SILVA, A. G. Avaliando a arborização urbana. Viçosa, MG: Aprenda Fácil, 2007. 346 p.

SCHIAVO FILHO, P. Considerações sobre elaboração de projetos de arborização. In: CURSO DE ATUALIZAÇÃO PROFISSIONAL EM MANEJO DE ARBORIZAÇÃO URBANA, 2. Rio de Janeiro: APEFERJ, 1999. p. 24-37

SOARES, M. P. Verdes urbanos e rurais: orientação para arborização de cidades e sítios campesinos. Porto Alegre: Cinco continentes, 1999. 2422 p.

SOUZA, M. L. Desenvolvimento de comunidade e participação. São Paulo: Cortez, 1993. $231 \mathrm{p}$. 